\title{
Layout Planning of a Distribution Center Based on SLP
}

\author{
Wujun Cao, Hanxing Hao*, Xinxin Wang \\ Institute of Management Engineering, Zhengzhou University, No. 100 science Avenue, Zhengzhou, China \\ 896023218@qq.com
}

Keywords: logistics industry, distribution centre, facility planning, SLP

\begin{abstract}
In recent years, the logistics industry in China has developed rapidly, and the logistics distribution centers have been built in various parts of China. In order to ensure the scientific and rational construction, it is necessary to make a thorough study on the planning and design of the distribution center. Firstly, the collected data and the formula are used to determine the area and the throughput of the distribution center. Then, the layout of the distribution area is planned by SLP method. The functional area is sorted by the flow rate calculation, and then the functional areas between the logistics relationship and non-logistics relationship, the functional area between the comprehensive correlation is obtained. Finally, the paper proposes a set of feasible facilities planning program.
\end{abstract}

\section{INTRODUCTION}

Modern logistics distribution center is the transfer point of material supply and sales, and plays an important role in the whole process of logistics operation (Qinqin Li, Wei Wang, Canjun Lu,2015). If the distribution center layout is not reasonable, it will not only affect the efficiency of logistics warehousing and distribution center logistics cost increase, and will increase the cost of social logistics warehousing, weakening the competitiveness of enterprises, so the reasonable layout of the distribution center is very important(Hui Li,Guowen Huang, Ershi Qi,2014).Layout is the core of facility planning and design, and it is one of the important links in the design and analysis of logistics system. At present, the layout design methods include pendulum method, mathematical model method, graphic method and system layout method (SLP)(Xin Shi,2014).SLP is the most practical and representative of the layout method, the first proposed by the RMuther. It combines the collected data and chart analysis and graphics model as a means to put the concept of the concept of planning and design analysis of the whole process, is the current layout of the mainstream design method (Yifei Shi ,2014).

Therefore, this paper takes city planning a comprehensive distribution center as the background, annual turnover, the distribution center of the storage capacity and the total area of parameter estimation firstly, then SLP method is used to design production facilities planning of the enterprise, through dividing operation unit of the enterprise, between the description of each operation unit shall determine the relationship. The optimum design plan of the enterprise, to improve the production efficiency, shorten the product cycle, can also provide support for other enterprise expansion and improvement

\section{DISTRIBUTION CENTER SCALE DESIGN}

\subsection{Case introduction}

The central city intends to set up a distribution center in its development zone. The function is targeted at the daily necessities of the city, the transportation of food and the transportation and distribution of urban consumer goods. Its main business for many varieties of small quantities of transport and distribution.

\subsection{Scale determination}

\subsubsection{Variable value}

- L : by statistics, the city's annual output of this area is 58 million tons;

- $\mathrm{i}_{1}$ :Taking into account the huge potential of China's third-party logistics and future logistics market economic development level, according to the national average, $i_{1}$ value of $20 \%$;

- $\mathrm{i}_{2}$ :Based on empirical analysis, If the local economy is highly marketed and the logistics market demand is large, then $i_{2}$ take a large value, such as the Yangtze River Delta and the Pearl River Delta region,Instead take a small value.As the city's logistics market demand is moderate. Therefore, $i_{2}$ takes a relatively middle value of $70 \%$;

- $\mathrm{i}_{3}$ :As the main business of the distribution center for the multi-species small batch of transport and distribution, so the total flow of logistics accounted for a small proportion of the logistics center, so take i value of $5 \%$

- $\alpha$ :As the distribution center goods flow faster, the utilization of its area is very high, so the unit production capacity $\alpha$ relatively small parameters,so $\alpha=30 \mathrm{t} / \mathrm{m}^{2}$.

According to the above numerical value, the scale of the distribution center is preliminarily determined:

$$
\mathrm{s}=\frac{\operatorname{Li}_{1} \mathrm{i}_{2} \mathrm{i}_{3} \alpha}{365}=33369 \mathrm{~m}^{2}
$$


So the distribution center area is about $33369 \mathrm{~m}^{2}$

\subsubsection{Warehouse capacity planning}

- Annual capacity calculation

$$
T=0.5 L \mathrm{i}_{1} \mathrm{i}_{2} \mathrm{i}_{3}=192850 \mathrm{t}
$$

Therefore, the distribution center on the throughput of about 1060 tons, the import volume of 530 tons each day.

- Turnaround number determined

According to statistics, turnover number $\mathrm{N}$ is about 28 times a year.

- Warehouse capacity determination

The capacity of the warehouse is calculated as: capacity = annual turnover / turnover times.so planned storage capacity is 7072 tons.

In view of the development of the distribution center and the short-term fluctuation of the storage volume, 7100 tons are taken here.

\section{DISTRIBUTION CENTER FACILITY PLANNING BASED ON SLP}

\subsection{Logistics flow setting in each function area of distribution center}

According to the above calculation results, the daily delivery volume of the case distribution center is 530 tons.The operation flow and logistics volume of the distribution center are shown in Figure 1.

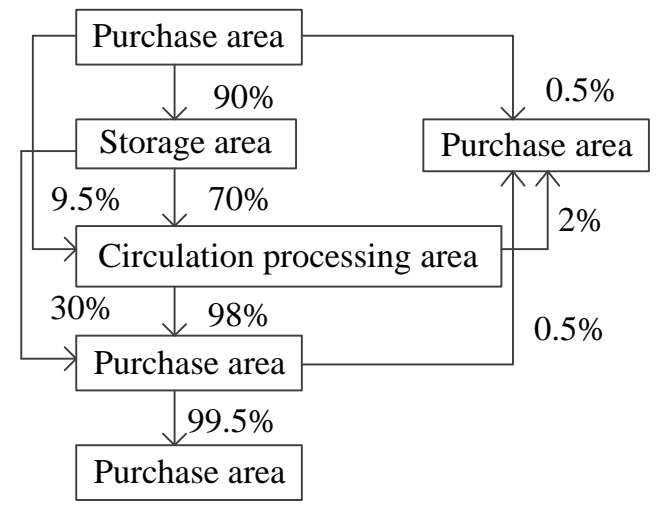

Figure 1: Operation process and logistics quantity

\subsection{Analysis of the relationship between operating units}

According to the main business of the distribution center and function, it is set to 9 functional areas, respectively: purchase area, storage area, circulation processing area, picking area, delivery area, reverse logistics operation area, office area, auxiliary operation area and service area. Each function area is a unit of work. For convenience, The 9 units are represented in number 1-9 in turn.

\subsubsection{Logistics interaction analysis}

According to the logistics volume shown in Table 1, we can calculate from the from-to chart of logistics intensity between every two functional areas. The logistics intensity of the operating unit not shown in the table is 0 .

SLP transforms the logistics intensity into five grades, which are represented by A, E, I, O and U respectively. The level is determined by the proportion of logistics routes or the proportion of the logistics undertaken. According to the above table, draw the operating unit logistics related table, as shown in Table 2.

Table 1: This caption has one line so it is centered.

\begin{tabular}{|c|c|c|c|}
\hline Units & Intensity (t) & Units & Intensity (t) \\
\hline $1-2$ & 477 & $3-4$ & 376.57 \\
\hline $1-3$ & 7.69 & $3-6$ & 7.69 \\
\hline $1-6$ & 2.65 & $4-5$ & 517.08 \\
\hline $2-3$ & 333.9 & $4-6$ & 2.59 \\
\hline $2-4$ & 143.1 & & \\
\hline
\end{tabular}

Table 2: Operating unit logistics related table

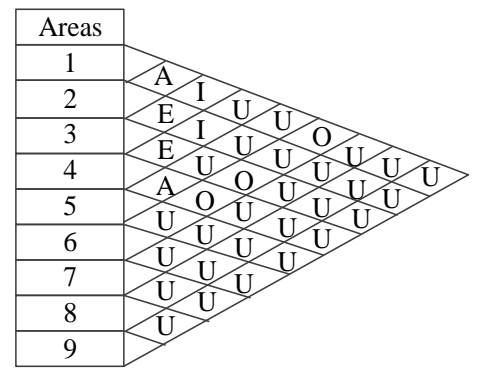

\subsubsection{Non - logistics interrelationship analysis}

Non - logistics relationship refers to the transmission of information and the frequency of services between regions, and the non - logistics relationship table of operating units is shown in table 3

\section{Table 3: Non - logistics relation table.}

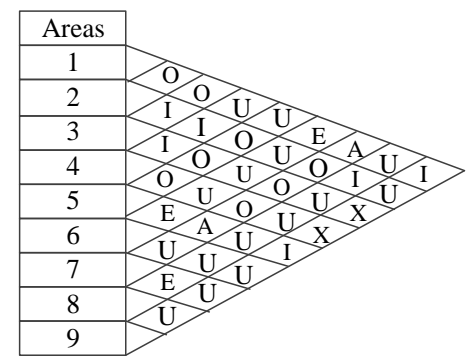

\subsubsection{Comprehensive correlation analysis}

It can be found that table 2 and table 3 are not consistent. so it need for further comprehensive analysis, taccording to the situation set the logistics relationship: non-logistics relationship $=3$ : 1 , obtained Operating units to calculate the relationship between the table and the operating unit to calculate the relationship between the table, and according to the results can be produced by the operating units of the comprehensive relationship between the table as shown in Table 4 .

According to the operating units of the comprehensive relationship between the table, come to the operating units of the comprehensive proximity ranking.

According to the operating units of the comprehensive relationship between the table, come to the operating units of the comprehensive proximity ranking. 
Table 4: Operating unit synthetic relation table.

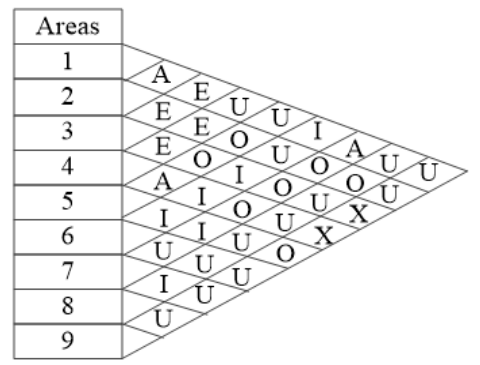

Table 5: Comprehensive proximity ranking table

\begin{tabular}{|c|c|c|}
\hline Operation unit & Score & Rank \\
\hline storage area & 13 & 1 \\
\hline picking area & 12 & 2 \\
\hline circulation processing area & 12 & 3 \\
\hline delivery area & 11 & 4 \\
\hline purchase area & 10 & 5 \\
\hline reverse logistics operation area & 8 & 6 \\
\hline office area & 7 & 7 \\
\hline auxiliary operation area & 3 & 8 \\
\hline service area & 0 & 9 \\
\hline
\end{tabular}

Finally, the position correlation diagram is shown, as shown in Figure 2

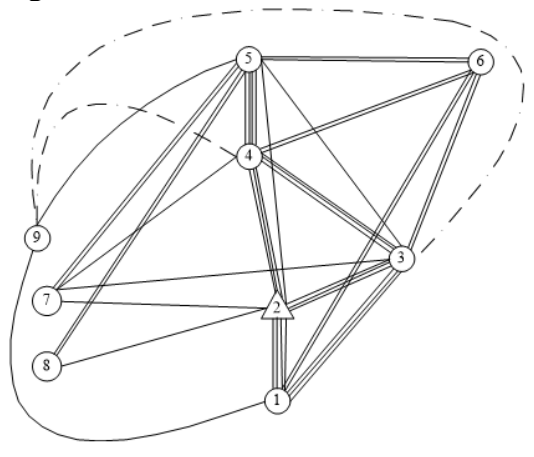

Figure 2: position correlation diagram

The layout diagram of the distribution center can be drawn from the job location diagram of figure 2, as shown in Figure 3.

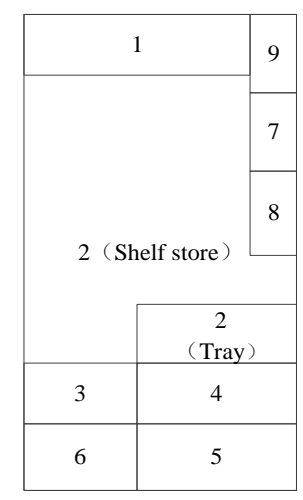

Figure 3: Layout plan of distribution center

\subsection{Detailed layout of case distribution center}

In the analysis of the relationship between the distribution center, the layout area of the distribution center is determined, but the specific area and the shape geometry of each function area are not taken into account, but the close relationship between the operating units The relative position between the functional areas.
After the plan of the distribution center of the distribution center is determined, the area occupied by the operating units of the distribution center and the related operating equipment of the distribution center shall be combined with the logistics operation area and equipment identified in the regional planning and facilities planning Make appropriate adjustments to reduce the regional overlap and the gap, you can get a detailed planning of the distribution center, as shown in Figure 5.

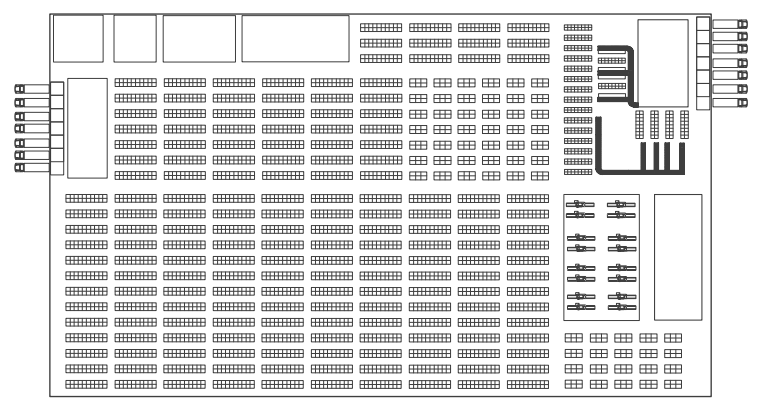

Figure 4: Detailed layout of distribution center

\section{CONCLUSIONS}

In this paper, the SLP method is used to analyze the facilities planning of a city's distribution center. Based on the analysis of the main business of the distribution center for small batch and multi-batch distribution, the operation unit is divided and the logistics and nonlogistics relationship between the operating units are analyzed, the logistics strength and non-logistics strength between the operating units are obtained. Finally, the comprehensive relationship between the operating units and the degree of comprehensive proximity are obtained, and a reasonable arrangement scheme is found, which is important to find out the optimal layout of distribution center significance.

Of course, the layout design of distribution center is a comprehensive technology, it involves many subjects, and there are many regulations in the design to follow. Therefore, the layout method of distribution center based on SLP still has many aspects to be further studied, such as a single operating area to determine how to take into account the logistics, safety, health and related laws and regulations, the layout of the design of how to take into account the design of the handling system.

\section{REFERENCES}

[1] Qinqin Li,Wei Wang,Canjun Lu,2015.Study on Program of Internal Function Layout of Modern Logistic Delivery Center, Railway Transport and Economy.37(8), pp.22-28.

[2] Hui Li, Guowen Huang, Ershi Qi,2014.Dynamic Facility Layout Problem Systems Based on Hybrid Ant Colony Optimization Algorithm, Journal of Industrial Engineering and Engineering Management. 01(28), pp.110-118.

[3] Xin Shi, 2014. Research on Production Facility Planning Based on SLP, Machine Design \& Research.01(30), pp.68-71.

[4] Yifei Shi ,2014. Study on Planning and Design of Logistics Centers Based on Improved SLP Approach, Logistics Technology.,07(33), pp.189-191. 